\title{
Estimation of the Separate Primary and Secondary Leakage Inductances of a Y- $\Delta$ Transformer Using Least Squares Method
}

\author{
Yong-Cheol Kang*, Byung-Eun Lee ${ }^{\dagger}$ and Tae-Keun Hwang**
}

\begin{abstract}
This paper proposes an estimation algorithm for the separate primary and secondary leakage inductances of a three phase $\mathrm{Y}-\Delta$ transformer using least squares method. The voltage equations from the primary and secondary windings are combined into a differential equation to estimate the separate primary and secondary leakage inductances in order to use the line current of the delta winding. Separate primary and secondary leakage inductances are obtained by applying least squares method to the differential equation. The performance of the proposed algorithm is validated under transient states, such as magnetic inrush and overexcitation, as well as in the steady state with various cut-off frequencies of low-pass filter. The proposed technique can accurately generate separate leakage inductances both in the steady and transient states.
\end{abstract}

Keywords: Leakage inductance, Delta winding current, Least squares method

\section{Introduction}

A transformer protection relay must be able to discriminate internal faults from all other operating conditions. Differential relays have been widely used for transformer protection. The relays, however, are prone to mal-operation during magnetic inrush or overexcitation. To prevent this, the relays adopt restraining or blocking signals derived from the current or the flux.

Second- and fifth-harmonic components are used for current derived restraints [1]-[3]. Harmonic restraints ensure stability during transformer energization and overexcitation; however, theses may reduce the operating sensitivity to internal faults. In addition, the restraints cause an operating time delay in the relay when an internal fault occurs. Threshold values for the second- and fifthharmonic components depend on the characteristics of the core of the transformer and the system conditions.

It has been reported that techniques [4]-[6] do not depend on the harmonic characteristics of the differential currents, but on the electro-magnetic differential equations. The operating speed of the relays is faster than the current differential relays using harmonic blocking schemes because additional blocking schemes are not required. Previously reported techniques [4]-[6] are unaffected by system conditions and core characteristics. However, the methods require the separate values of the primary and secondary winding resistances and the leakage inductances. Separate winding resistances can be obtained experimentally, whereas separate leakage inductances cannot be obtained

$\dagger$ Corresponding Author: Department of Electrical Engineering, Chonbuk National University, Korea. (mpeclab@chonbuk.ac.kr),

* Department of Electrical Engineering, Chonbuk National University, Korea. (yckang@chonbuk.ac.kr)

** Department of Electrical engineering, Chonbuk National University, Korea. (taekeuny@chonbuk.ac.kr)

Received: January 29, 2010; Accepted: March 16, 2010 using short-circuit test of the transformer.

Estimation algorithms for the parameters of a transformer have been proposed [7], [8] using least squares method in the time domain. The method can estimate the separate values of the primary and secondary winding resistances and leakage inductances. Unfortunately, it uses the winding current. Thus, to apply this algorithm to a transformer with a delta winding, a current transformer to measure the winding current should be installed inside the transformer. This inevitably increases the size and cost of the transformer.

This paper proposes an algorithm, which estimates the separate values of the primary and secondary leakage inductances of a Y- $\Delta$ transformer using least squares method in the time domain. The proposed algorithm combines the primary and secondary voltage equations into a differential equation for the separate primary and secondary leakage inductances in order to use the line currents that are available. Applying least squares method to the differential equation gives the separate primary and secondary leakage inductances. The performance of the proposed estimation algorithm is investigated by varying the cut-off frequency of a low-pass filter under the transient states, such as magnetic inrush and overexcitation, and under various normal operating conditions with Electromagnetic Transients Program (EMTP) generated data.

\section{Estimation of the Separate Primary and Secondary Leakage Inductances of a Three-phase Y- $\Delta$ Transformer}

Fig. 1 shows the connection diagram and the equivalent circuit of a three-phase Y- $\Delta$ transformer. Voltage equations of the primary and secondary windings are represented by: 


$$
\begin{gathered}
v_{A}=R_{A} i_{A}+L_{l A} \frac{d i_{A}}{d t}+e_{A}, \\
v_{B}=R_{B} i_{B}+L_{l B} \frac{d i_{B}}{d t}+e_{B}, \\
v_{C}=R_{C} i_{C}+L_{l C} \frac{d i_{C}}{d t}+e_{C}, \\
v_{a b}=R_{a b} i_{a b}+L_{l a b} \frac{d i_{a b}}{d t}+e_{a b}, \\
v_{b c}=R_{b c} i_{b c}+L_{l b c} \frac{d i_{b c}}{d t}+e_{b c}, \text { and } \\
v_{c a}=R_{c a} i_{c a}+L_{l c a} \frac{d i_{c a}}{d t}+e_{c a} .
\end{gathered}
$$

Here, $e_{A}, e_{B}$, and $e_{C}$ can be calculated from (1)-(3), but $e_{a b}, e_{b c}$, and $e_{c a}$ cannot be calculated from (4)-(6) because it is not practical to measure $i_{a b}, i_{b c}$, and $i_{c a}$. Therefore, information about these currents is unavailable.

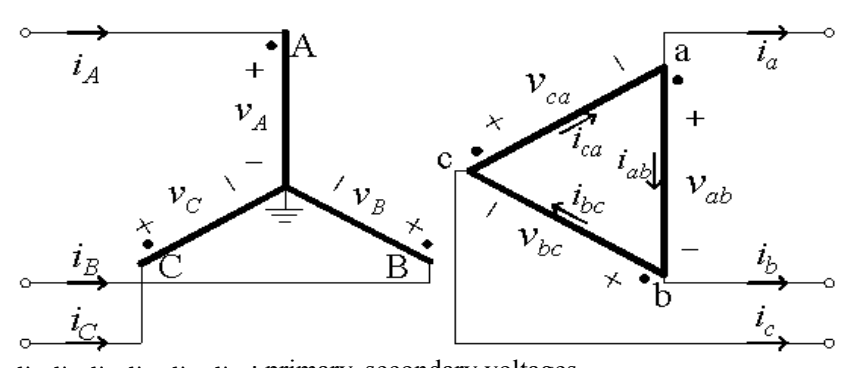

$v_{A}, v_{B}, v_{C}, v_{a b}, v_{b c}, v_{c a}$ : primary, secondary voltages

$i_{A}, i_{B}, i_{C}, i_{a b}, i_{b c}, i_{c a}$ : primary, secondary winding currents

$i_{a}, i_{b}, i_{c}:$ secondary line currents

(a) Connection diagram of a $\mathrm{Y}-\Delta$ transformer

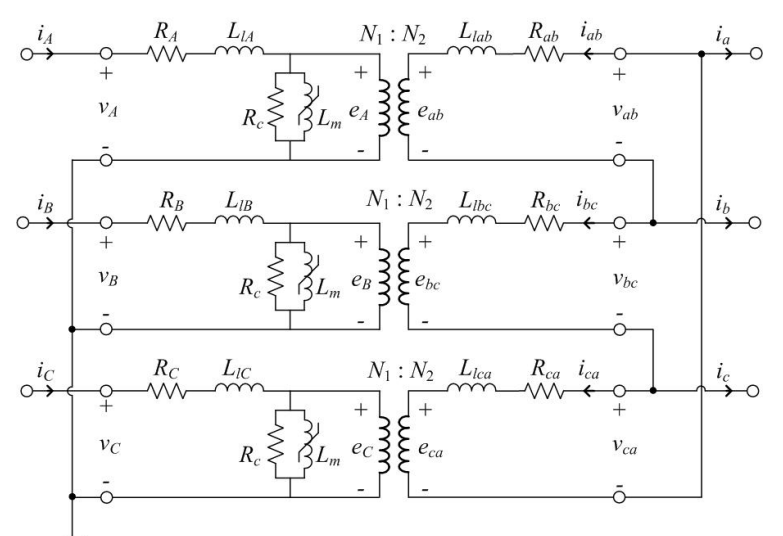

$e_{A}, e_{B}, e_{C}, e_{a b}, e_{b c}, e_{c a}$ : induced voltages

$L_{l A}, L_{l B}, L_{l C}, L_{l a b}, L_{l b c}, L_{l c a}$ : leakage inductances

$R_{A}, R_{B}, R_{C}, R_{a b}, R_{b c}, R_{c a}$ : primary and secondary winding resistances

$R_{c}$ : core-loss resistance

$L_{m}$ : magnetizing inductance

$N_{1}, N_{2}$ : number of turns of primary and secondary windings (b) Equivalent circuit of a Y- $\Delta$ transformer

Fig. 1. Connection diagram and equivalent circuit of a Y- $\Delta$ transformer.
In this paper, to use the line currents instead of the winding currents, the relationship of (7) between the line currents and the winding currents is valid.

$$
i_{c a}-i_{a b}=i_{a}, i_{a b}-i_{b c}=i_{b}, i_{b c}-i_{c a}=i_{c}
$$

If there is no internal fault, the assumption in (8) is valid.

$$
R_{a b} \approx R_{b c} \approx R_{c a}=R_{2}, L_{l a b} \approx L_{l b c} \approx L_{l c a}=L_{l 2}
$$

Subtracting (4) from (6), (5) from (4), and (6) from (5) yields:

$$
\begin{gathered}
e_{c a}-e_{a b}=v_{c a}-v_{a b}-R_{2} i_{a}-L_{l 2} \frac{d i_{a}}{d t} \\
e_{a b}-e_{b c}=v_{a b}-v_{b c}-R_{2} i_{b}-L_{l 2} \frac{d i_{b}}{d t}, \text { and } \\
e_{b c}-e_{c a}=v_{b c}-v_{c a}-R_{2} i_{c}-L_{l 2} \frac{d i_{c}}{d t}
\end{gathered}
$$

Therefore, although $e_{a b}, e_{b c}$, and $e_{c a}$ cannot be calculated, the differences between the two phases can be calculated from (9)-(11). Similarly, the equations of the primary winding corresponding to (12)-(14) can be derived from (1)-(3) as represented by:

$$
\begin{gathered}
e_{C}-e_{A}=v_{C}-v_{A}-\left(R_{C} i_{C}-R_{A} i_{A}\right)-\left(L_{l C} \frac{d i_{C}}{d t}-L_{l A} \frac{d i_{A}}{d t}\right), \\
e_{A}-e_{B}=v_{A}-v_{B}-\left(R_{A} i_{A}-R_{B} i_{B}\right)-\left(L_{l A} \frac{d i_{A}}{d t}-L_{l B} \frac{d i_{B}}{d t}\right),
\end{gathered}
$$

and

$$
e_{B}-e_{C}=v_{B}-v_{C}-\left(R_{B} i_{B}-R_{C} i_{C}\right)-\left(L_{l B} \frac{d i_{B}}{d t}-L_{l C} \frac{d i_{C}}{d t}\right) \text {. }
$$

As in the case of the secondary winding, if there is no internal fault, the resistances and leakage inductances of the primary winding can be assumed to be equal, i.e., $R_{C}=R_{A}$ $=R_{1}$ and $L_{1 C}=L_{1 A}=L_{l 1}$. Hence, (12) can be simplified as:

$$
e_{C}-e_{A}=v_{C}-v_{A}-R_{1}\left(i_{C}-i_{A}\right)-L_{l 1}\left(\frac{d i_{C}}{d t}-\frac{d i_{A}}{d t}\right) \text {. }
$$

Equations (13) and (14) can be similarly simplified. However, for convenience, only (12) was simplified in this paper.

If there is no internal fault, (16) is valid.

$$
\frac{e_{A}}{e_{a b}}=\frac{N_{1}}{N_{2}}, \frac{e_{B}}{e_{b c}}=\frac{N_{1}}{N_{2}}, \frac{e_{C}}{e_{c a}}=\frac{N_{1}}{N_{2}}
$$


As mentioned above, $e_{A}, e_{B}$, and $e_{C}$ can be directly calculated from observable voltages and currents; however, $e_{a b}$, $e_{b c}$, and $e_{c a}$ cannot. Thus, (16) cannot be directly used. Therefore, the relationship of (17) to the induced voltages of the primary and secondary windings is used in this paper. Equation (17) is a necessary and sufficient condition for (16).

$$
\frac{e_{C}-e_{A}}{e_{c a}-e_{a b}}=\frac{N_{1}}{N_{2}}, \frac{e_{A}-e_{B}}{e_{a b}-e_{b c}}=\frac{N_{1}}{N_{2}}, \frac{e_{B}-e_{C}}{e_{b c}-e_{c a}}=\frac{N_{1}}{N_{2}}
$$

Combining (9) and (15) using (17) yields:

$$
\begin{aligned}
& v_{C}-v_{A}-R_{1}\left(i_{C}-i_{A}\right)-L_{l 1}\left(\frac{d i_{C}}{d t}-\frac{d i_{A}}{d t}\right) \\
& =a\left(v_{c a}-v_{a b}-R_{2} i_{a}-L_{l 2} \frac{d i_{a}}{d t}\right),
\end{aligned}
$$

where $a=N_{1} / N_{2}$.

For the expression of $L_{l 1}$ and $L_{l 2}$, rewriting (18) yields:

$$
\begin{aligned}
& \left(\frac{d i_{C}}{d t}-\frac{d i_{A}}{d t}\right) L_{l 1}+\left(-a \frac{d i_{a}}{d t}\right) L_{l 2} \\
& =-\left(i_{C}-i_{A}\right) R_{1}+a i_{a} R_{2}+v_{C}-v_{A}-a\left(v_{c a}-v_{a b}\right)
\end{aligned} .
$$

Simplifying (19) gives:

$$
\begin{gathered}
S_{n 1}^{\prime} L_{l 1}+S_{n 2}^{\prime} L_{l 2}=Y_{n}^{\prime}, \\
\text { where } S_{n 1}^{\prime}=\frac{d i_{C}}{d t}-\frac{d i_{A}}{d t}, S_{n 2}^{\prime}=-a \frac{d i_{a}}{d t} \text { and } \\
Y_{n}^{\prime}=-\left(i_{C}-i_{A}\right) R_{1}+a i_{a} R_{2}+v_{C}-v_{A}-a\left(v_{c a}-v_{a b}\right),
\end{gathered}
$$

Integration of (20) from $t_{0}$ to $t$ yields:

$$
S_{n 1} L_{l 1}+S_{n 2} L_{l 2}=Y_{n}
$$

With n sample values, (21) can be represented as:

$$
\left[\begin{array}{cc}
S_{11} & S_{12} \\
S_{21} & S_{22} \\
\vdots & \vdots \\
S_{n 1} & S_{n 2}
\end{array}\right]\left[\begin{array}{l}
L_{l 1} \\
L_{l 2}
\end{array}\right]=\left[\begin{array}{c}
Y_{1} \\
Y_{2} \\
\vdots \\
Y_{n}
\end{array}\right]
$$

Using matrix notation yields:

$$
[\mathbf{S}][\mathbf{L}]=[\mathbf{Y}],
$$

where $[\mathrm{S}],[\mathrm{L}]$, and $[\mathrm{Y}]$ are $\mathrm{n} \times 2,2 \times 1$ and $\mathrm{n} \times 1$ matrices, respectively.

To estimate [L], applying least squares method to (23) yields:

$$
[\mathbf{L}]=\left\{[\mathbf{S}]^{T}[\mathbf{S}]\right\}^{-1}[\mathbf{S}]^{T}[\mathbf{Y}] .
$$

Using (24), we obtain the separate primary and secondary leakage inductances of a three-phase $\mathrm{Y}-\Delta$ transformer.

The proposed algorithm operates in the time domain, so the separate values of the primary and secondary leakage inductances can be estimated even in the transient state, such as magnetic inrush and overexcitation with nonsinusoidal voltages and currents.

\section{Case Studies}

Fig. 2 shows a single-line diagram of the simulated system with the power frequency of $60 \mathrm{~Hz}$. A two-winding three-phase Y- $\Delta$ transformer (55 MVA, $154 / 12.7 \mathrm{kV}$ ) was used to generate the voltages and currents of the transformer using EMTP. The hysteresis characteristics of the transformer core were modeled using a type-96 element; the saturation point of (40 A, $334 \mathrm{Vs})$ was selected to use HYSDAT, a subroutine of EMTP. The correct values of the leakage inductance of the transformer are $L_{l 1}=76.40 \mathrm{mH}$ and $L_{l 2}=1.559 \mathrm{mH}$, respectively.

As mentioned in Section 2, the proposed algorithm can estimate the separate primary and secondary leakage inductances even under the transient states, such as magnetic inrush and overexcitation. Thus, the performance of the algorithm was verified under the transient states as well as in the steady state, by varying the cut-off frequency of a low-pass filter.

The sampling rates $\left(N_{s}\right)$ of 64 and 128 samples/cycle $(\mathrm{s} / \mathrm{c})$ were used for the case studies. All voltages and currents were made to pass through the 2 nd order Butterworth filters with stop-band cut-off frequencies of 480-3840 Hz.

In this paper, 64 and 128 sample values of the voltages and currents were used for the least squares method for the 64 and $128 \mathrm{~s} / \mathrm{c}$ sample rates, respectively. This means $n=$ 64 for $64 \mathrm{~s} / \mathrm{c}$ and $n=128$ for $128 \mathrm{~s} / \mathrm{c}$ in (22).

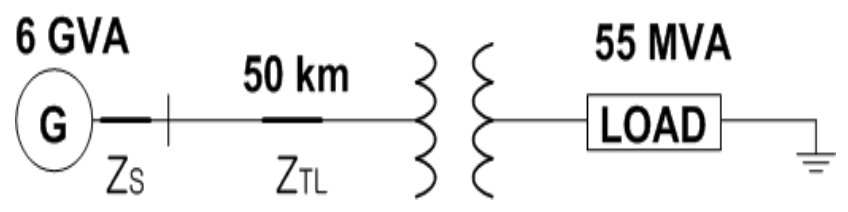

Fig. 2. Model system studied.

\subsection{Error Analysis for the Load Current (Case 1)}

The performance of the proposed estimation algorithm can be affected by the magnitude of the load current. Thus, this subsection shows the test results for a full load and a half load current.

Fig. 3 shows the three-phase primary and secondary voltages and currents of the transformer when using a full 


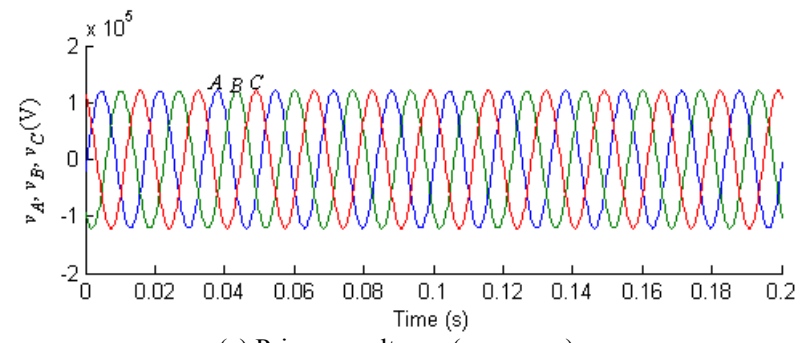

(a) Primary voltages $\left(v_{A}, v_{B}, v_{C}\right)$

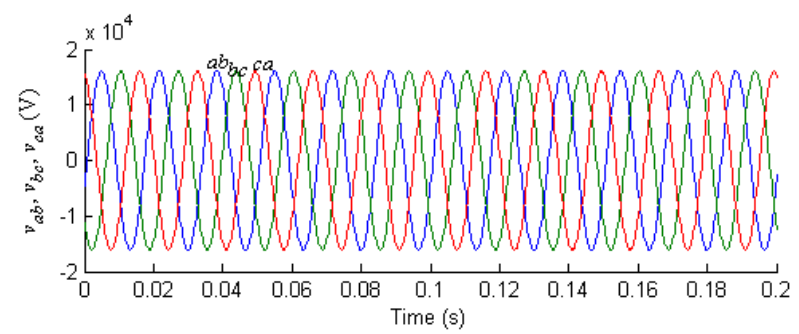

(b) Secondary voltages $\left(v_{a b}, v_{b c}, v_{c a}\right)$

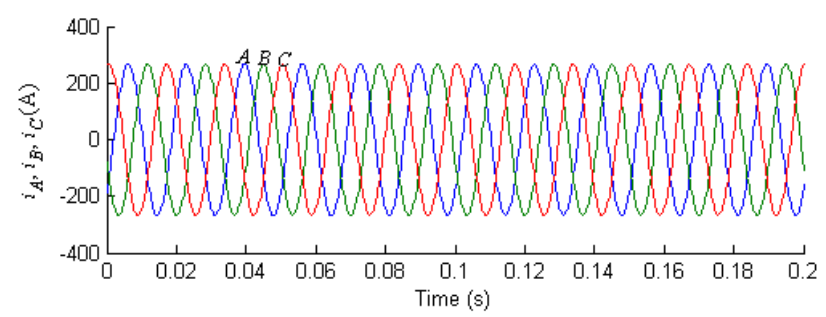

(c) Primary currents $\left(i_{A}, i_{B}, i_{C}\right)$

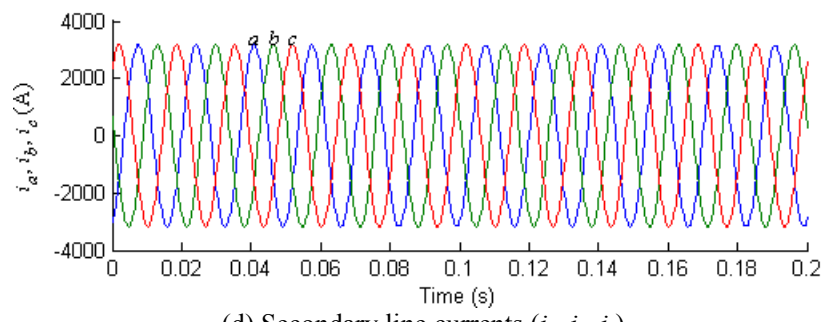

(d) Secondary line currents $\left(i_{a}, i_{b}, i_{c}\right)$

Fig. 3. Three-phase voltages and currents on a full load.

load. With the voltages and currents in Fig. 3, the primary and secondary leakage inductances were estimated by varying the sampling rate and the cut-off frequency of the low-pass filter.

As an example, Fig. 4 shows the correct and estimated primary and secondary leakage inductances for 1 second in the case where the sample rate is $64 \mathrm{~s} / \mathrm{c}$ and the $f_{c}$ is 1920 $\mathrm{Hz}$; as can be seen, the solid and dotted lines represent the correct and estimated values, respectively. The result indicates that the estimated values are very close to the correct value.

Tables 1 and 2 show the mean, standard deviation (SD), and percent errors of the estimated leakage inductances for 1 second by varying $f_{c}$ in the case of a full load and a half load, respectively. The mean errors in Tables 1 and 2 remain very small (i.e., below $2 \%$ ). The same is true with the SDs (i.e., less than $3 \%$ of the mean of $L_{l 1}$ and $L_{l 2}$ ) when $f_{c}$ is $480 \mathrm{~Hz}$ or higher. Results indicate that the proposed technique accurately estimates the primary and secondary leakage inductances regardless of the load conditions.

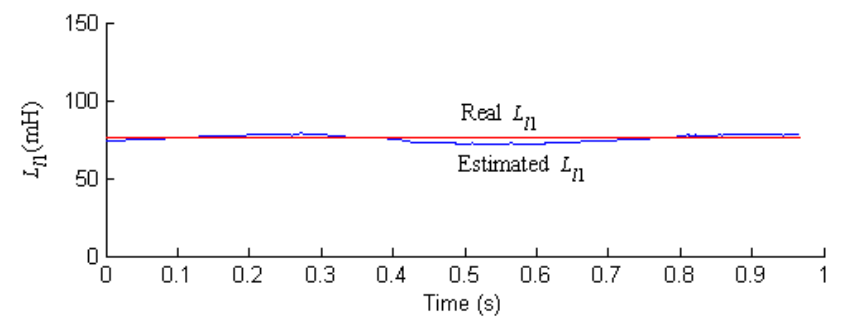

(a) Estimated $L_{l 1}$

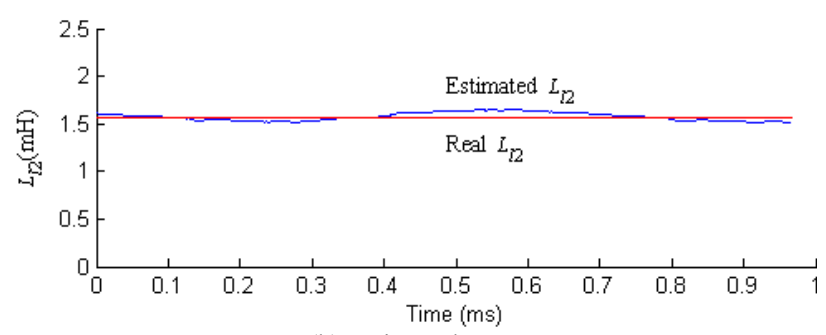

(b) Estimated $L_{l 2}$

Fig. 4. Estimated $L_{l 1}$ and $L_{l 2}$ for $64 \mathrm{~s} / \mathrm{c}$ with $f_{c}$ of $1920 \mathrm{~Hz}$ on a full load.

Table 1. Full load

\begin{tabular}{ccccccc} 
(a) $N_{s}=64 \mathrm{~s} / \mathrm{c}$ \\
\hline $\begin{array}{c}f_{c} \\
(\mathrm{~Hz})\end{array}$ & $\begin{array}{c}\text { Mean of } \\
L_{l 1}(\mathrm{mH})\end{array}$ & $\begin{array}{c}\text { Mean of } \\
L_{l 2}(\mathrm{mH})\end{array}$ & $\begin{array}{c}\mathrm{SD} \text { of } L_{l 1} \\
(\mathrm{mH})\end{array}$ & $\begin{array}{c}\text { SD of } L_{l 2} \\
(\mathrm{mH})\end{array}$ & $\begin{array}{c}\text { Error of } \\
L_{l 1}(\%)\end{array}$ & $\begin{array}{c}\text { Error of } \\
L_{l 2}(\%)\end{array}$ \\
\hline 1920 & 75.453 & 1.577 & 2.124 & 0.041 & 1.243 & -1.144 \\
\hline 960 & 75.737 & 1.571 & 1.481 & 0.028 & 0.871 & -0.760 \\
\hline 480 & 75.726 & 1.571 & 2.090 & 0.046 & 0.886 & -0.775 \\
\hline 240 & 75.646 & 1.573 & 4.656 & 0.100 & 0.991 & -0.880 \\
\hline 120 & 75.530 & 1.575 & 9.525 & 0.201 & 1.142 & -1.035 \\
\hline
\end{tabular}

\begin{tabular}{|c|c|c|c|c|c|c|}
\hline $\begin{array}{c}f_{c} \\
(\mathrm{~Hz})\end{array}$ & $\begin{array}{l}\text { Mean of } \\
L_{l 1}(\mathrm{mH})\end{array}$ & $\begin{array}{l}\text { Mean of } \\
L_{12}(\mathrm{mH})\end{array}$ & $\begin{array}{l}\text { SD of } L_{l 1} \\
(\mathrm{mH})\end{array}$ & $\begin{array}{l}\text { SD of } L_{l 2} \\
(\mathrm{mH})\end{array}$ & $\begin{array}{c}\text { Error of } \\
L_{l 1}(\%)\end{array}$ & $\begin{array}{l}\text { Error of } \\
L_{12}(\%)\end{array}$ \\
\hline 3840 & 76.271 & 1.562 & 2.422 & 0.048 & 0.172 & -0.167 \\
\hline 1920 & 76.475 & 1.558 & 2.189 & 0.043 & -0.094 & 0.105 \\
\hline 960 & 76.492 & 1.557 & 1.526 & 0.029 & -0.117 & 0.129 \\
\hline 480 & 76.095 & 1.566 & 2.054 & 0.046 & 0.403 & -0.403 \\
\hline 240 & 75.736 & 1.573 & 4.649 & 0.100 & 0.873 & -0.882 \\
\hline 120 & 75.590 & 1.576 & 9.433 & 0.199 & 1.063 & -1.076 \\
\hline
\end{tabular}

Table 2. Half a load

(a) $N_{s}=64 \mathrm{~s} / \mathrm{c}$

\begin{tabular}{ccccccc}
\hline $\begin{array}{c}f_{c} \\
(\mathrm{~Hz})\end{array}$ & $\begin{array}{c}\text { Mean of } \\
L_{l 1}(\mathrm{mH})\end{array}$ & $\begin{array}{c}\text { Mean of } \\
L_{l 2}(\mathrm{mH})\end{array}$ & $\begin{array}{c}\mathrm{SD} \text { of } L_{l 1} \\
(\mathrm{mH})\end{array}$ & $\begin{array}{c}\mathrm{SD} \text { of } L_{l 2} \\
(\mathrm{mH})\end{array}$ & $\begin{array}{c}\text { Error of } \\
L_{l 1}(\%)\end{array}$ & $\begin{array}{c}\text { Error of } \\
L_{l 2}(\%)\end{array}$ \\
\hline 1920 & 75.062 & 1.584 & 1.818 & 0.037 & 1.755 & -1.601 \\
\hline 960 & 75.259 & 1.580 & 1.620 & 0.033 & 1.496 & -1.344 \\
\hline 480 & 75.871 & 1.568 & 0.292 & 0.006 & 0.695 & -0.536 \\
\hline
\end{tabular}

\begin{tabular}{|c|c|c|c|c|c|c|}
\hline $\begin{array}{c}f_{c} \\
(\mathrm{~Hz})\end{array}$ & $\begin{array}{l}\text { Mean of } \\
L_{l 1}(\mathrm{mH})\end{array}$ & $\begin{array}{l}\text { Mean of } \\
L_{l 2}(\mathrm{mH})\end{array}$ & $\begin{array}{c}\text { SD of } L_{l 1} \\
(\mathrm{mH})\end{array}$ & $\begin{array}{c}\text { SD of } L_{l 2} \\
(\mathrm{mH})\end{array}$ & $\begin{array}{l}\text { Error of } \\
L_{l 1}(\%) \\
\end{array}$ & $\begin{array}{l}\text { Error of } \\
L_{12}(\%)\end{array}$ \\
\hline 3840 & 75.631 & 1.575 & 1.929 & 0.039 & 1.010 & -0.975 \\
\hline 1920 & 75.683 & 1.573 & 1.857 & 0.038 & 0.942 & -0.906 \\
\hline 960 & 75.752 & 1.572 & 1.662 & 0.034 & 0.852 & -0.815 \\
\hline 480 & 76.150 & 1.564 & 0.302 & 0.006 & 0.331 & -0.289 \\
\hline
\end{tabular}

\subsection{Error Analysis for $80 \%$ of the Rated Voltage (Case 2)}

The proposed algorithm can be affected by the magni- 
tude of the voltage. Thus, this subsection describes the results if the magnitude of the voltage is decreased to $80 \%$ of the rated voltage. Table 3 shows the mean, SD, and percent errors of the estimated leakage inductances for $1 \mathrm{sec}-$ ond by varying $f_{c}$ from $480 \mathrm{~Hz}$ to half of the sampling frequency, i.e., $1920 \mathrm{~Hz}$ for $64 \mathrm{~s} / \mathrm{c}$ and $3840 \mathrm{~Hz}$ for $128 \mathrm{~s} / \mathrm{c}$. In this case, the mean errors remain below $1 \%$. However, the SDs of $L_{l 1}$ and $L_{l 2}$ are less than $3.123 \mathrm{mH}$ and $0.064 \mathrm{mH}$, corresponding to $4 \%$ of the mean and are slightly larger than those in Case 1.

Table 3. $80 \%$ of the rated voltage

(a) $N_{s}=64 \mathrm{~s} / \mathrm{c}$

\begin{tabular}{ccccccc}
\hline $\begin{array}{c}f_{c} \\
(\mathrm{~Hz})\end{array}$ & $\begin{array}{c}\text { Mean of } \\
L_{l 1}(\mathrm{mH})\end{array}$ & $\begin{array}{c}\text { Mean of } \\
L_{l 2}(\mathrm{mH})\end{array}$ & $\begin{array}{c}\mathrm{SD} \text { of } L_{l 1} \\
(\mathrm{mH})\end{array}$ & $\begin{array}{c}\mathrm{SD} \text { of } L_{l 2} \\
(\mathrm{mH})\end{array}$ & $\begin{array}{c}\text { Error of } \\
L_{l 1}(\%)\end{array}$ & $\begin{array}{c}\text { Error of } \\
L_{l 2}(\%)\end{array}$ \\
\hline 1920 & 75.759 & 1.570 & 2.951 & 0.060 & 0.842 & -0.715 \\
\hline 960 & 76.037 & 1.565 & 2.598 & 0.053 & 0.478 & -0.346 \\
\hline 480 & 75.647 & 1.573 & 1.186 & 0.024 & 0.989 & -0.867 \\
\hline
\end{tabular}

\begin{tabular}{|c|c|c|c|c|c|c|}
\hline $\begin{array}{c}f_{c} \\
(\mathrm{~Hz})\end{array}$ & $\begin{array}{l}\text { Mean of } \\
L_{l 1}(\mathrm{mH}) \\
\end{array}$ & $\begin{array}{l}\text { Mean of } \\
L_{12}(\mathrm{mH})\end{array}$ & $\begin{array}{c}\text { SD of } L_{l 1} \\
(\mathrm{mH})\end{array}$ & $\begin{array}{c}\text { SD of } L_{12} \\
(\mathrm{mH})\end{array}$ & $\begin{array}{l}\text { Error of } \\
L_{l 1}(\%)\end{array}$ & $\begin{array}{c}\text { Error of } \\
L_{12}(\%)\end{array}$ \\
\hline 3840 & 76.770 & 1.551 & 3.123 & 0.064 & -0.480 & 0.507 \\
\hline 1920 & 76.904 & 1.549 & 3.048 & 0.062 & -0.656 & 0.685 \\
\hline 960 & 76.845 & 1.550 & 2.647 & 0.054 & -0.579 & 0.607 \\
\hline 480 & 76.145 & 1.564 & 1.217 & 0.025 & 0.338 & -0.326 \\
\hline
\end{tabular}

\subsection{Error Analysis under Magnetic Inrush (Case 3)}

As mentioned in Section 2, the proposed algorithm can estimate the primary and secondary inductances even in the transient states, such as magnetic inrush and overexcitation. This subsection shows the test results for magnetic inrush, i.e., when the transformer is energized. Fig. 5 shows the primary and secondary voltages as well as the currents for magnetic inrush. Fig. 6 shows the primary and secondary leakage inductances estimated with the voltages and currents in Fig. 5 for 1 second when there are 64 samples per cycle and $f_{c}$ is $1920 \mathrm{~Hz}$. Results indicate that the estimated values are very close to the correct values, except for the spike that occurred at the instance when the transformer is energized.

Table 4 shows the mean, SD, and percent errors of the

Table 4. Magnetic inrush

\begin{tabular}{ccccccc} 
(a) $N_{s}=64 \mathrm{~s} / \mathrm{c}$ \\
\hline $\begin{array}{c}f_{c} \\
(\mathrm{~Hz})\end{array}$ & $\begin{array}{c}\text { Mean of } \\
L_{l 1}(\mathrm{mH})\end{array}$ & $\begin{array}{c}\text { Mean of } \\
L_{l 2}(\mathrm{mH})\end{array}$ & $\begin{array}{c}\mathrm{SD} \text { of } L_{l 1} \\
(\mathrm{mH})\end{array}$ & $\begin{array}{c}\text { SD of } L_{l 2} \\
(\mathrm{mH})\end{array}$ & $\begin{array}{c}\text { Error of } \\
L_{l 1}(\%)\end{array}$ & $\begin{array}{c}\text { Error of } \\
L_{l 2}(\%)\end{array}$ \\
\hline 1920 & 75.284 & 1.582 & 1.222 & 0.026 & 1.464 & 1.429 \\
\hline 960 & 75.514 & 1.576 & 1.313 & 0.028 & 1.162 & 1.075 \\
\hline 480 & 75.746 & 1.571 & 1.764 & 0.038 & 0.859 & 0.723 \\
\hline \multicolumn{7}{c}{$(\mathrm{b}) N_{s}=128 \mathrm{~s} / \mathrm{c}$} \\
\hline$f_{c}$ & Mean of & Mean of & $\mathrm{SD}$ of $L_{l 1}$ & $\mathrm{SD}$ of $L_{l 2}$ & Error of & Error of \\
$(\mathrm{Hz})$ & $L_{l 1}(\mathrm{mH})$ & $L_{l 2}(\mathrm{mH})$ & $(\mathrm{mH})$ & $(\mathrm{mH})$ & $L_{l 1}(\%)$ & $L_{l 2}(\%)$ \\
\hline 3840 & 75.874 & 1.569 & 1.199 & 0.026 & 0.691 & 0.661 \\
\hline 1920 & 76.029 & 1.567 & 1.171 & 0.025 & 0.489 & 0.459 \\
\hline 960 & 76.054 & 1.566 & 1.267 & 0.027 & 0.456 & 0.415 \\
\hline 480 & 76.034 & 1.566 & 1.746 & 0.038 & 0.482 & 0.431 \\
\hline \multicolumn{7}{c}{}
\end{tabular}

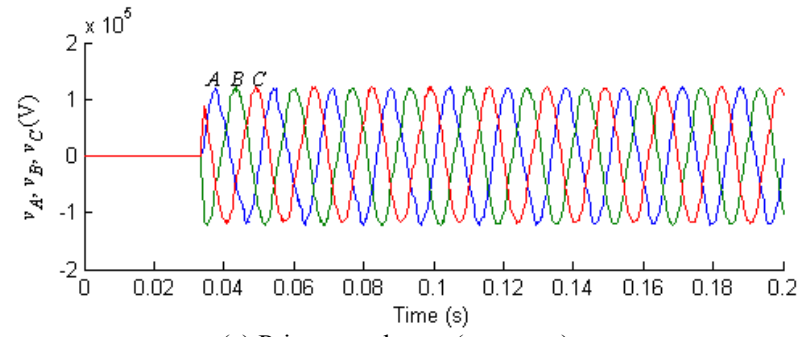

(a) Primary voltages $\left(v_{A}, v_{B}, v_{C}\right)$

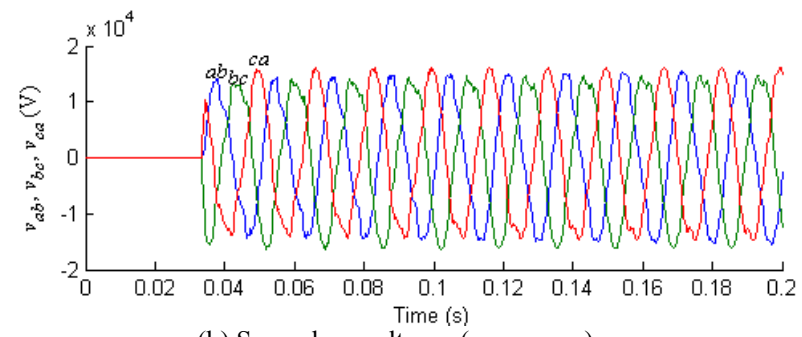

(b) Secondary voltages $\left(v_{a b}, v_{b c}, v_{c a}\right)$

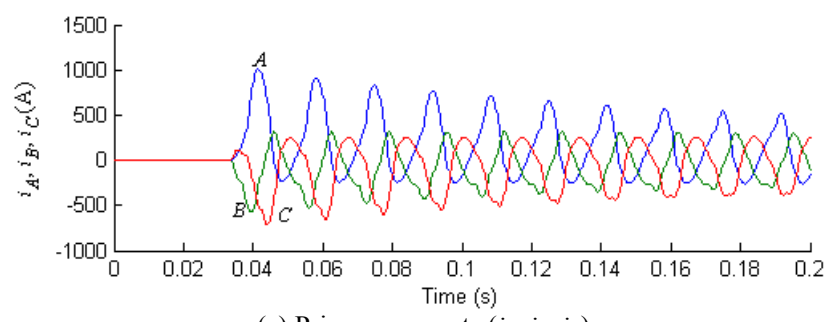

(c) Primary currents $\left(i_{A}, i_{B}, i_{C}\right)$

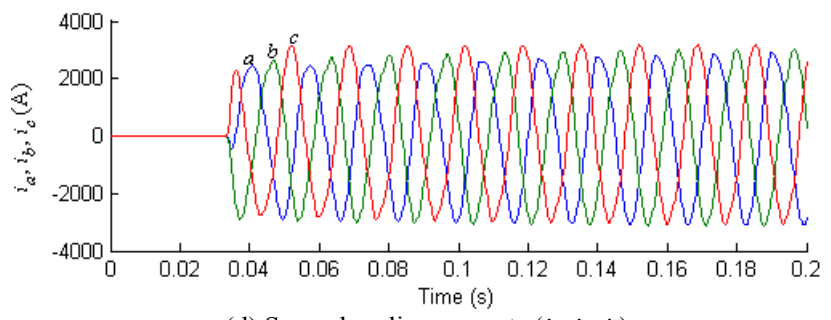

(d) Secondary line currents $\left(i_{a}, i_{b}, i_{c}\right)$

Fig. 5. Three-phase voltages and currents for a magnetic inrush.

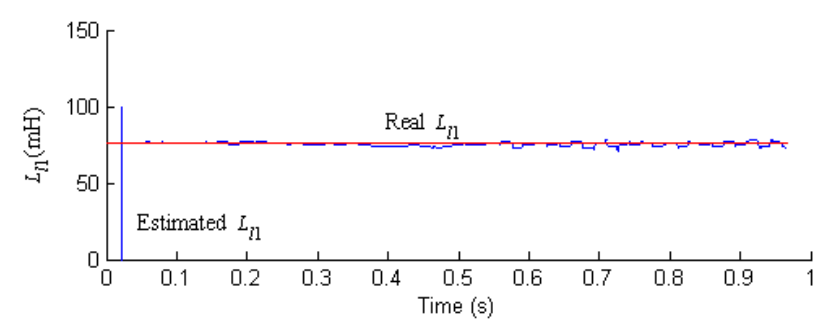

(a) Estimated $L_{l 1}$

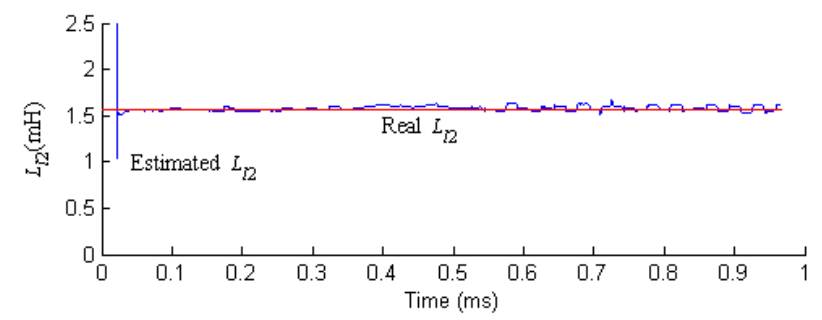

(b) Estimated $L_{12}$

Fig. 6. Estimated $L_{l 1}$ and $L_{l 2}$ for $64 \mathrm{~s} / \mathrm{c}$ with $f_{c}$ of $1920 \mathrm{~Hz}$ for a magnetic inrush. 
estimated leakage inductances for 1 second by varying $f_{c}$ in the case of magnetic inrush. The mean errors remain below $1.5 \%$ and the SDs remain less than $2.5 \%$ of the mean of $L_{l 1}$ and $L_{l 2}$. Results indicate that the proposed estimation technique accurately estimates the leakage inductances even in the presence of a magnetic inrush.

\subsection{Error Analysis under Overexcitation (Case 4)}

This subsection shows the test results under overexcitation, i.e., when $120 \%$ of the rated voltage is applied to the transformer. Fig. 7 shows the primary and secondary voltages and currents in Case 4. Fig. 8 shows the primary and secondary leakage inductances estimated with the voltages and currents in Fig. 7 when there are 64 samples per cycle and $f_{c}$ is $1920 \mathrm{~Hz}$. Results indicate that the estimated values are very close to the correct values, except for a few samples around the instance of overexcitation.

Table 5 shows the mean, SD, and percent errors of the

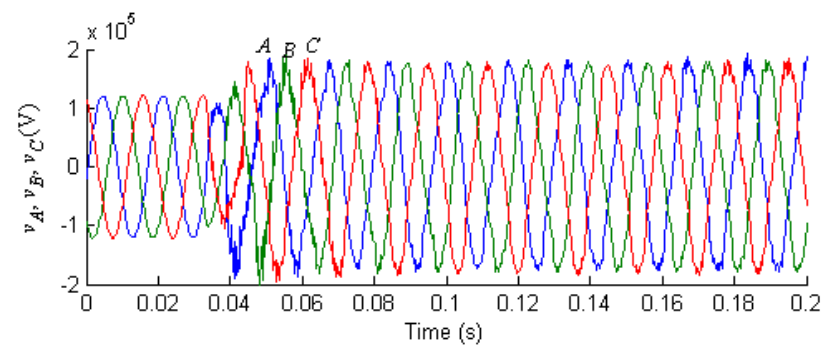

(a) Primary voltages $\left(v_{A}, v_{B}, v_{C}\right)$

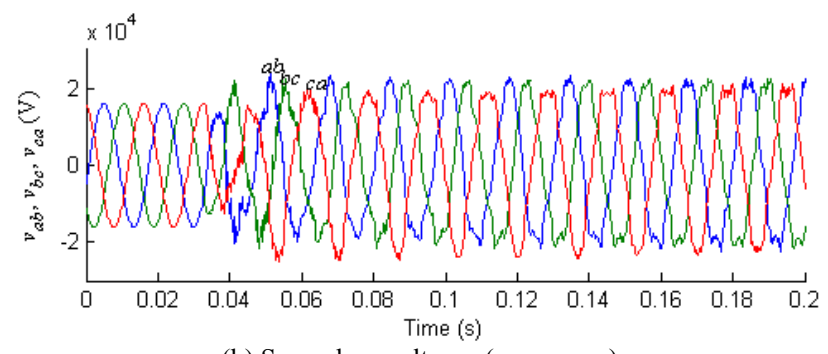

(b) Secondary voltages $\left(v_{a b}, v_{b c}, v_{c a}\right)$

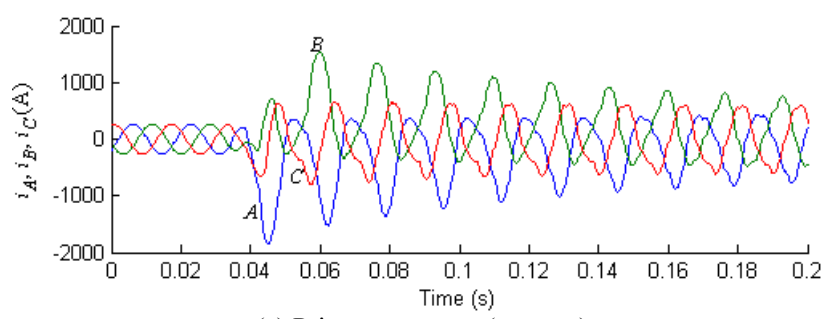

(c) Primary currents $\left(i_{A}, i_{B}, i_{C}\right)$

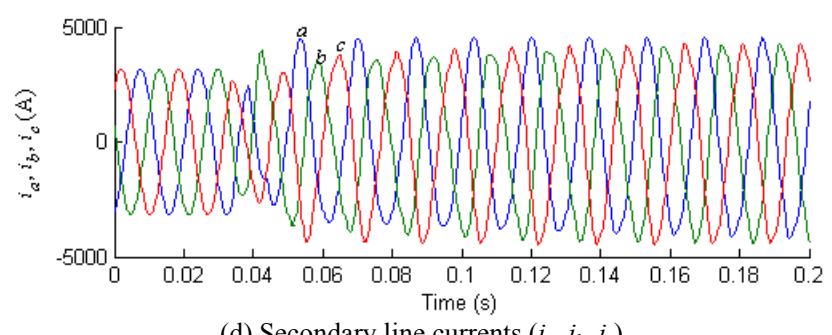

(d) Secondary line currents $\left(i_{a}, i_{b}, i_{c}\right)$

Fig. 7. Three-phase voltages and currents for an overexcitation.

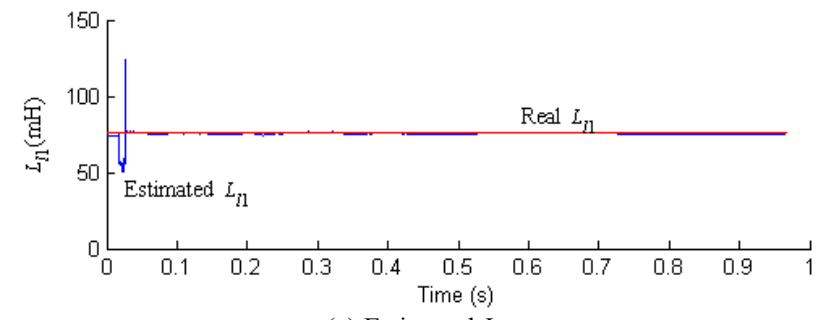

(a) Estimated $L_{l 1}$

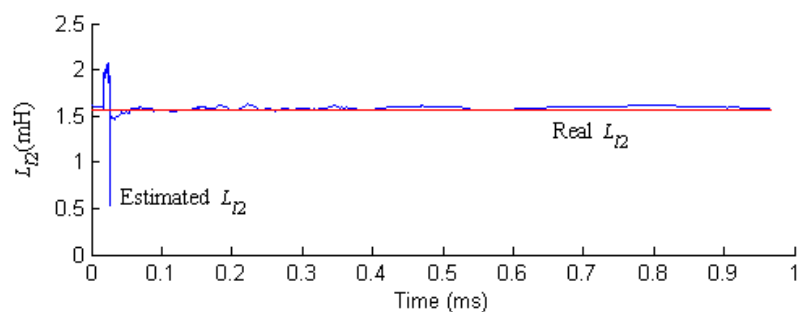

(b) Estimated $L_{l 2}$

Fig. 8. Estimated $L_{l 1}$ and $L_{l 2}$ for $64 \mathrm{~s} / \mathrm{c}$ with $f_{c}$ of $1920 \mathrm{~Hz}$ for an overexcitation.

Table 5. Overexcitation

\begin{tabular}{ccccccc} 
(a) $N_{s}=64 \mathrm{~s} / \mathrm{c}$ \\
\hline $\begin{array}{c}f_{c} \\
(\mathrm{~Hz})\end{array}$ & $\begin{array}{c}\text { Mean of } \\
L_{l 1}(\mathrm{mH})\end{array}$ & $\begin{array}{c}\text { Mean of } \\
L_{l 2}(\mathrm{mH})\end{array}$ & $\begin{array}{c}\mathrm{SD} \text { of } L_{l 1} \\
(\mathrm{mH})\end{array}$ & $\begin{array}{c}\mathrm{SD} \text { of } L_{l 2} \\
(\mathrm{mH})\end{array}$ & $\begin{array}{c}\text { Error of } \\
L_{l 1}(\%)\end{array}$ & $\begin{array}{c}\text { Error of } \\
L_{l 2}(\%)\end{array}$ \\
\hline 1920 & 75.346 & 1.588 & 2.241 & 0.046 & 1.383 & -1.835 \\
\hline 960 & 75.661 & 1.581 & 1.165 & 0.026 & 0.971 & -1.419 \\
\hline 480 & 75.936 & 1.575 & 1.328 & 0.037 & 0.610 & -0.987 \\
\hline (b) $N_{s}=128 \mathrm{~s} / \mathrm{c}$ & \multicolumn{1}{c}{} & & & \\
\hline$f_{c}$ & Mean of & Mean of & SD of $L_{l 1}$ & SD of $L_{l 2}$ & Error of & Error of \\
$(\mathrm{Hz})$ & $L_{l 1}(\mathrm{mH})$ & $L_{l 2}(\mathrm{mH})$ & $(\mathrm{mH})$ & $(\mathrm{mH})$ & $L_{l 1}(\%)$ & $L_{l 2}(\%)$ \\
\hline 3840 & 75.605 & 1.578 & 1.982 & 0.041 & 1.044 & -1.209 \\
\hline 1920 & 75.915 & 1.575 & 1.349 & 0.029 & 0.638 & -1.008 \\
\hline 960 & 75.996 & 1.574 & 0.846 & 0.021 & 0.532 & -0.934 \\
\hline 480 & 76.062 & 1.573 & 1.358 & 0.038 & 0.446 & -0.907 \\
\hline
\end{tabular}

estimated leakage inductances by varying $f_{c}$ during a period of overexcitation. The mean errors remain below $2 \%$ and the SDs remain less than $3 \%$ of the mean of $L_{l 1}$ and $L_{l 2}$. Results indicate that the proposed estimation technique accurately estimates the leakage inductances even when the transformer is overexcited.

\section{Conclusion}

This paper proposed an estimation algorithm for the separate primary and secondary leakage inductances of a Y- $\Delta$ transformer using least squares method. The proposed method combines the primary and secondary voltage equations to use the line currents of the delta side. From the combined equation, the separate values of the primary and secondary leakage inductances are estimated from the terminal voltages and currents using least squares method.

The performance of the algorithm was investigated by varying the cut-off frequency of the low-pass filter, the load current, and the magnitude of the voltage. Test results 
were also presented for the transient states, such as magnetic inrush and overexcitation. For both of the sampling rates (64 and $128 \mathrm{~s} / \mathrm{c})$, the estimation errors remained about $2 \%$ and the SDs remain less than $4 \%$ of the mean of the leakage inductances when $f_{c}$ was $480 \mathrm{~Hz}$ or higher. Test results clearly indicate that the proposed algorithm can accurately estimate the leakage inductances in various operating conditions including magnetic inrush and overexcitation using the line currents of the delta side.

\section{Acknowledgements}

This research was supported by Basic Science Research Program through the National Research Foundation of Korea(NRF) funded by the Ministry of Education, Science and Technology.

\section{References}

[1] C. D. Hayward, "Harmonic-Current-Restrained Relays for Transformer Differential Protection," AIEE Trans., Vol. 60, pp. 377-382, 1941.

[2] R. L. Sharp and W. E. Glassburn, "A Transformer Differential Relay with Second-Harmonic Restraint", AIEE Trans. Part III, Vol. 77, pp. 913-918, 1958.

[3] C. H. Einvall and J. R. Linders, "A Three-phase Differential Relay for Transformer Protection", IEEE Trans. on PAS, Vol. 94, No. 6, pp. 1971-1980, Nov./Dec. 1975.

[4] K. Inagaki, M, Higaki, Y. Matsui, K. Kurita, "Digital Protection Method for Power Transformer Based on an Equivalent Circuit Composed of Inverse Inductance", IEEE Trans. on PWRD, Vol.3, No.4, pp. 1501-1510, Oct. 1988

[5] M. S. Sachdev, T. S. Sidhu, and H. C. Wood, "A Digital Relaying Algorithm for Detection Transformer Winding Faults," IEEE Trans. on PWRD, Vol. 4, No. 3, pp. 1638-1648, Jul. 1989.

[6] Y. C. Kang and B. E. Lee, "A Transformer Protection Relay Based on Induced Voltages," KIEE Trans on Power Engineering, Vol. 3-A, No. 2, pp. 70-78, Jun. 2003.
[7] A. Keyhani, S.M. Miri, and S. Hao, "Parameter Estimation for Power Transformer Models from TimeDomain Data," IEEE Trans. PWRD, Vol. 1, No. 3, pp. 140-146, July 1986.

[8] S. A. Soliman, R. A. Alammari, and M. A. Mostafa, "On-line estimation of transformer model parameters”, LESCOPE'04, 2004 Large Engineering Systems Conf. on Power Engineering, Westin Nova Scotian, Canada, 28-30. pp. 170-178, Jul. 2004.

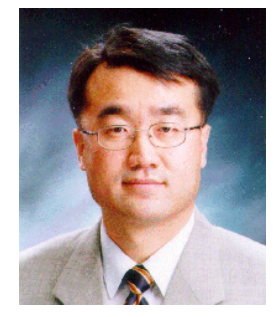

Yong-Cheol Kang received his B.S., M.S. and Ph.D degrees from Seoul National University, Korea in 1991, 1993 and 1997, respectively. He is currently a Professor in Chonbuk National University, Korea. His research interest is on the development of new protection systems for power systems using digital signal processing techniques.

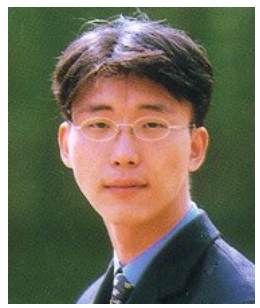

Byung-Eun Lee received his B.S. and M.S. degrees from Chonbuk National University, Korea in 1999 and 2001, respectively. He is currently studying for his Ph.D. degree at Chonbuk National University. His research interest is in power system protection.

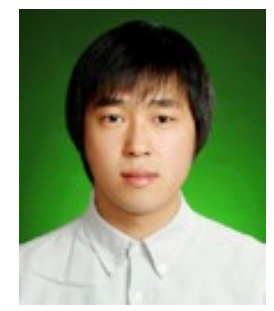

Tae-keun Hwang received his B.S. and M.S. degrees from Chonbuk National University, Korea in 2006 and 2008, respectively. His research interest is power system protection. 